\title{
MYC Immunohistochemistry Predicts MYC Rearrangements by FISH
}

\author{
Julum Nwanze ${ }^{1,2 *}$, Momin T. Siddiqui ${ }^{1}$, Keith A. Stevens ${ }^{1}$, Debra Saxe $^{1}$ \\ and Cynthia Cohen ${ }^{1}$ \\ 'Department of Pathology and Laboratory Medicine, Emory University Hospital, Atlanta, GA, United States, \\ ${ }^{2}$ Department of Pathology and Laboratory Medicine, Tulane University Hospital, New Orleans, LA, United States
}

\section{OPEN ACCESS}

Edited by:

Ala-Eddin Al Moustafa, Qatar University, Qatar

Reviewed by:

Shahid Pervez,

Aga Khan University, Pakistan Francesco Di Raimondo, University of Catania, Italy

Zuheir Alshehabi,

Tishreen University, Syria

*Correspondence: Julum Nwanze cnwanze@tulane.edu

Specialty section:

This article was submitted to Molecular and Cellular Oncology, a section of the journal Frontiers in Oncology

Received: 22 June 2017 Accepted: 25 August 2017 Published: 21 September 2017

Citation:

Nwanze J, Siddiqui MT, Stevens KA,

Saxe D and Cohen C (2017) MYC Immunohistochemistry Predicts MYC Rearrangements by FISH.

Front. Oncol. 7:209. doi: 10.3389/fonc.2017.00209
MYC is the proto-oncogene classically associated with Burkitt lymphoma (BL) located at chromosomal locus $8 q 24$. Rearrangements of MYC are seen in nearly $100 \%$ of BL but have been reported in 3-16\% of diffuse large B-cell lymphomas (DLBCLs). Rearrangements of MYC are tested for by flourescence in situ hybridization (FISH). In this study, we compared immunohistochemistry $(\mathrm{IHC})$ using a monoclonal antibody directed against the human Myc protein to the current method, FISH. 31 cases were identified that had been tested for MYC rearrangements by FISH over 27 months with heterogeneity in the diagnoses: $5 \mathrm{BL} ; 10$ DLBCL; 3 B-cell lymphoma unclassifiable between DLBCL and BL; 5 B-cell lymphoma not otherwise specified; 1 EBV-related B-cell lymphoma; 1 composite CLL/SLL-large cell lymphoma; and 6 designated as high-grade or aggressive B-cell lymphoma. Analysis by FISH was performed as part of the clinical workup, where a MYC rearrangement is defined as a split fusion signal in at least $5.7 \%$ of cells. Myc- $\mathrm{HC}$ was interpreted as a qualitative positive (overexpressed) or negative (not overexpressed) result. 12 cases (39\%) were positive for MYC rearrangements by FISH. Overall, 13 cases (42\%) showed Myc overexpression by IHC, 11 of which harbored a MYC rearrangement by FISH. There were two false positives and one false negative. Thus, Myc-IHC predicted a MYC rearrangement by FISH with $92 \%$ sensitivity and $89 \%$ specificity. We can thus conclude that Myc-IHC should be a potentially useful screening tool for identifying lymphomas that may harbor a MYC rearrangement.

Keywords: $M Y C$, immunohistochemistry, Burkitt lymphoma, in situ hybridization, $M Y C$ rearrangement

\section{INTRODUCTION}

The $M Y C$ proto-oncogene encodes a multifunctional, nuclear phosphoprotein that plays a role in cell cycle progression, apoptosis, and cellular transformation (1). MYC was first discovered as the cellular homolog of the retroviral V-MYC oncogene identified from studies of oncogenic retroviruses $(2,3)$. Soon after, chromosomal translocations juxtaposing MYC to immunoglobulin enhancers were documented in B-cell Burkitt lymphomas (BLs) (4). These were located at chromosomal locus 8q24 (4). Subsequently, mutations, overexpression, rearrangement, and translocation of this gene have been associated with various hematopoietic tumors, leukemias, and lymphomas (5).

A major effect of $M Y C$ is B-cell proliferation $(6,7)$. MYC gene alterations have been identified in mature B-cell neoplasms that are usually associated with an aggressive clinical behavior (8). In the United States, mature B-cell neoplasms account for approximately three-quarters of all lymphoid neoplasms (9). They comprise the majority of diffuse large B-cell lymphoma (DLBCL), BL, chronic 
lymphocytic leukemia/small lymphocytic lymphoma (CLL/ SLL), follicular lymphoma, and plasma cell neoplasms (9). B-cell neoplasms are also the fourth most common childhood cancers accounting for about $6 \%$ of pediatric malignancies with the most prevalent entities being BL (43\%) and diffuse B-cell lymphoma (13\%) (10).

C-Myc, N-Myc, and L-Myc are the three members of the Myc oncoprotein family known to play a role in the pathogenesis of numerous human neoplastic diseases (11). C-Myc overexpression is invariably associated with BL (12). Furthermore, rearrangements of the $M Y C$ gene are seen in nearly $100 \%$ of $\mathrm{BL}$ with the most common translocation variant being $\mathrm{t}(8 ; 14)$ (q24; q32) (8), which accounts for approximately $85 \%$ of cases (13). Other less common translocations, such as $\mathrm{t}(2 ; 8)(\mathrm{p} 12 ; \mathrm{q} 24)$ and $\mathrm{t}(8 ; 22)$ (q24; q11), account for the remaining $15 \%$ of cases (13). In contrast, DLBCL that includes a heterogeneous group of intermediate to high-grade mature B-cell neoplasms is reported to have rearrangements of MYC in 3-16\% of cases (14).

Myc overexpression that results from dysregulation in the cell cycle of the Myc protein can be assayed by Western blot or immunohistochemistry (IHC) (15). There is increasing evidence that Myc overexpression has a prognostic importance that may trump cytogenetic findings. There is, as yet, no definitive evidence of a role as a predictive biomarker (15).

Rearrangements of MYC are typically tested for by fluorescence in situ hybridization (FISH). This method is currently considered the most accurate method for detection of oncogene amplification in human tumors (16) and is the gold standard for prediction of $M Y C$ rearrangement (17). However, the procedure is laborious, demanding, and expensive due to the need for a fluorescence microscope (16).

Immunohistochemistry is less tedious to perform and less expensive than FISH. It has the potential to reduce the number of FISH specimens if specificity was high (15). Recently, a monoclonal antibody became commercially available for IHC, made by Epitomics (Burlingame, CA, USA). It is a rabbit antihuman immunoglobulin G molecule, clone Y69 (18) produced from a synthetic peptide that corresponds to residues in the $\mathrm{N}$-terminus of human C-Myc. The antibody also bears cross-reactivity to mouse and rat C-Myc (18).

The purpose of this study is to evaluate the effectiveness of Myc-IHC in predicting MYC rearrangement by FISH (the current gold standard) in mature B-cell lymphomas.

\section{MATERIALS AND METHODS}

A search was made through the surgical pathology files of Emory University Hospital, Atlanta, GA, USA, for cases that had been tested for MYC rearrangements by FISH. A total of 31 cases were identified over 27 months (May 2011-July 2013) with heterogeneity in the diagnoses: $5 \mathrm{BL} ; 10 \mathrm{DLBCL} ; 3 \mathrm{~B}$-cell lymphoma unclassifiable between DLBCL and BL; 5 B-cell lymphoma not otherwise specified (NOS); 1 EBV-related B-cell lymphoma; 1 composite CLL/SLL-large cell lymphoma; and 6 designated as high-grade or aggressive B-cell lymphoma. All samples had been obtained in accordance with guidelines approved by the Emory IRB committee.

\section{Myc IHC}

Sections $(5 \mu \mathrm{m})$ of formalin-fixed, paraffin-embedded tissue are tested for the presence of antigen using the Bond Polymer Refine Detection Kit (DAB chromogen) (Leica Microsystems, Bannockburn, IL, USA). The detection system avoids the use of streptavidin and biotin and, therefore, eliminates non-specific staining as a result of endogenous biotin. All steps are performed on the Leica Bond Maxx III automated system. Specimens are deparaffinized and antigen retrieved $(\mathrm{pH} 6.0$ in citrate buffer for $20 \mathrm{~min}$ ) on the instrument. All slides are incubated with rabbit monoclonal antibody (Epitomics, clone Y69; 1:100; Abcam, Cambridge, MA, USA) for $15 \mathrm{~min}$, with post-primary polymer for $8 \mathrm{~min}$, blocked with $3 \%$ hydrogen peroxide for $5 \mathrm{~min}$, 3,3-diaminobenzidine (DAB, brown chromogen) for $10 \mathrm{~min}$, and hematoxylin as counterstain for $5 \mathrm{~min}$. These incubations were performed at room temperature; between incubations, sections were washed with Tris-buffered saline (Bond wash solution). Coverslipping was performed using the Tissue-Tek SCA (Sakura Finetek USA, Inc., Torrance, CA, USA) coverslipper. Positive controls of known positive tissues (BL) and negative controls with specific antibody replaced with Tris buffer were run with the patient/study slides.

Myc-IHC was interpreted by the authors, blinded to the FISH result, as a qualitative positive (overexpressed) or negative (not overexpressed) result. A positive result is represented by a strong Myc nuclear staining in greater than $50 \%$ of the tumor cells. A negative result is represented by a usually faint staining in a small percentage of cells (less than 50\%).

\section{Fluorescence In Situ Hybridization for MYC Gene Rearrangements}

FISH performed at Emory University was carried out using formalin-fixed, paraffin-embedded tissues, with $4 \mu \mathrm{m}$ sections mounted on positively charged slides. Slides were deparaffinated on a slide warmer for $2 \mathrm{~h}$. The slides were processed on a VP 2000 (Abbott Molecular, Abbott Park, IL, USA), which includes pretreatment with protease. After slides were processed, $5 \mu \mathrm{l}$ of MYC break apart probe (Abbott Molecular, Inc.) was added, and the slides were coverslipped and sealed with rubber cement. The slides were then placed in a hybridization chamber overnight at $37^{\circ} \mathrm{C}$. Slides were washed with $2 \times \mathrm{SSC} / 0.3 \mathrm{NP}-40$ and dehydrated with EtOH. Slides are counterstained with $10 \mu \mathrm{LAPI}$ and chilled in the freezer for a minimum of $20 \mathrm{~min}$. A total of 200 cells were analyzed by two different readers each reading 100 cells. The specimen was considered positive for a MYC rearrangement if $>6 \%$ of the cells demonstrate a single fusion and a separate green and red signal.

\section{RESULTS}

Table $\mathbf{1}$ is a summary of the results of Myc-IHC and FISH by diagnosis. Figure 1 shows micrographs of IHC and FISH slides. 13/31 cases showed overexpression of Myc by IHC (Figure 1A). This is in contrast to $12 / 31(38.7 \%)$ cases that were positive for MYC rearrangements by FISH with the break-apart probe (Figure 1B). One case of B-cell lymphoma unclassifiable with features intermediate between DLBCL and BL and one case of 
TABLE 1 | Summary of results by diagnosis.

\begin{tabular}{|c|c|c|c|}
\hline Diagnosis & Number (\%) & $\begin{array}{c}\text { Myc overexpression by } \\
\text { immunohistochemistry (\%) }\end{array}$ & $\begin{array}{c}\text { MYC rearrangement } \\
\text { by FISH (\%) }\end{array}$ \\
\hline Burkitt lymphoma (BL) or "consistent with BL" & $5(100)$ & $5(100)$ & $5(100)$ \\
\hline Diffuse large B-cell lymphoma (DLBCL) & $10(100)$ & $0(0)$ & $1(10)$ \\
\hline B-cell lymphoma unclassifiable with features intermediate between DLBCL and BL & $3(100)$ & $3(100)$ & $2(66.67)$ \\
\hline EBV-related B-cell lymphoma & $1(100)$ & $0(0)$ & $0(0)$ \\
\hline Composite CLL/SLL-large cell lymphoma & $1(100)$ & $0(0)$ & $0(0)$ \\
\hline B-cell lymphoma, not otherwise specified & $5(100)$ & $2(40)$ & $1(20)$ \\
\hline "High-grade"/"aggressive" B-cell lymphoma & $6(100)$ & $3(50)$ & $3(50)$ \\
\hline Total & $31(100)$ & $13(41.9)$ & $12(38.7)$ \\
\hline
\end{tabular}

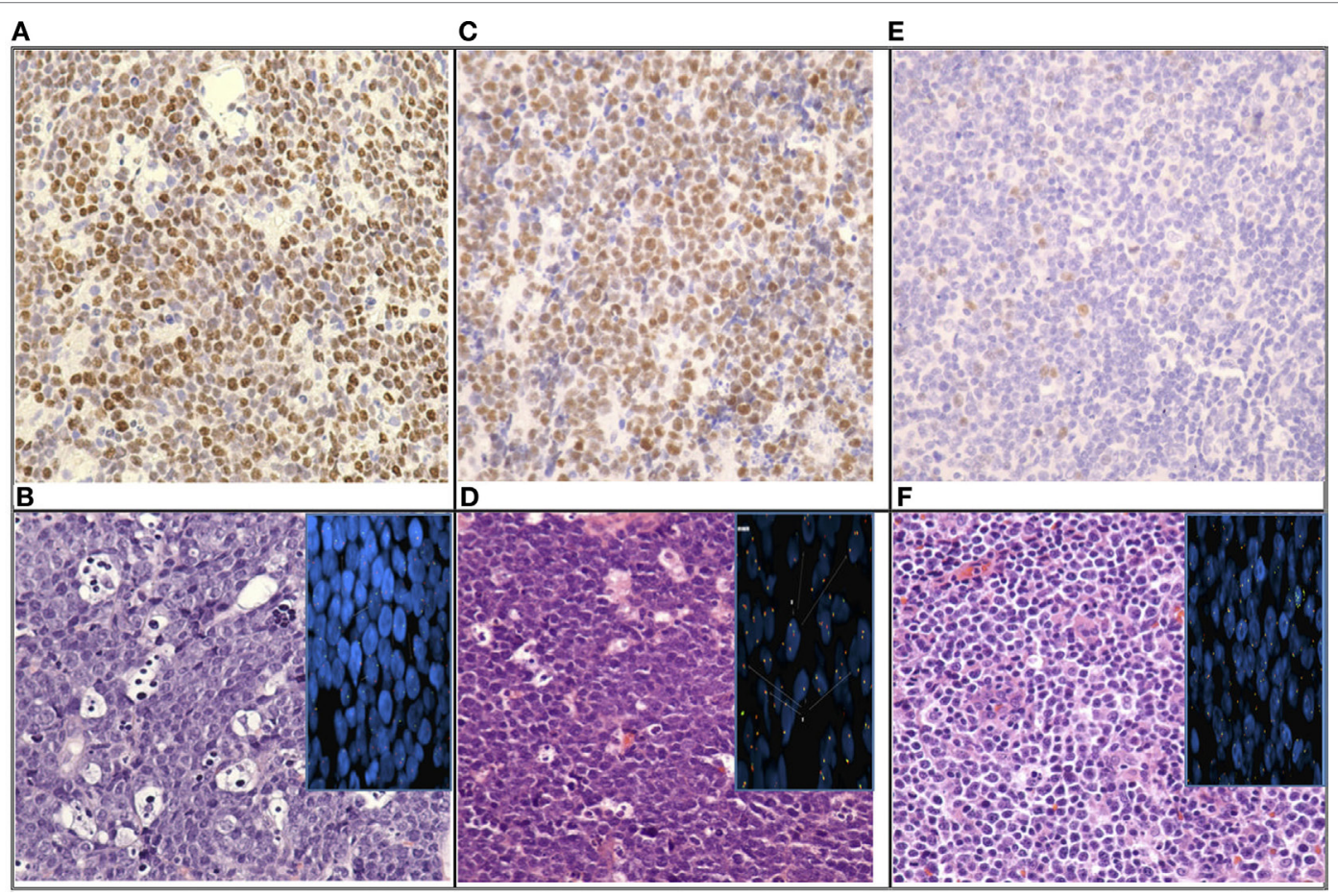

FIGURE 1 Micrographs of immunohistochemistry and FISH slides; (A) "True positive": Myc nuclear staining in nearly 100\% of tumor cells; (B) "True positive": Burkitt lymphoma (BL) (H/E) with MYC rearrangement by FISH (inset); (C) "False positive": Myc nuclear staining in nearly 100\% of tumor cells; (D) "False positive" B-cell lymphoma unclassifiable with features intermediate between diffuse large B-cell lymphoma (DLBCL) and BL (H/E) without MYC rearrange by FISH (inset); (E) "True negative": Myc nuclear staining faint in a small percentage of cells; (F) "True negative": DLBCL (H/E) without MYC rearrangement by FISH (inset) (image magnification: $4 \times)$.

B-cell lymphoma NOS showed Myc overexpression by IHC. Both cases, however, failed to show a rearrangement by FISH and were thus regarded as IHC false positives (Figure 1E,F). The presence of polysomy of chromosome 8 was noted. One case of DLBCL that showed a MYC rearrangement by FISH was negative by IHC, which was regarded as a false negative. Figure 2 shows the percentages of positive cases for each test.

Table 2 gives results of the statistical analysis. When compared with MYC gene arrangements by FISH, Myc-IHC has a sensitivity of $91.6 \%$ and a specificity of $89.4 \%$. The positive predictive value in this group of morphologically aggressive-appearing lymphomas was $84.6 \%$, and the negative predictive value was $94.4 \%$. Chi-squared analysis also demonstrated a strong correlation between MYC gene arrangements and Myc-IHC $(p<0.005)$. Kappa analysis between both tests gave a score of 0.80 .

\section{DISCUSSION}

MYC is a significant oncogene, and its deregulation has been shown to lead to the development of aggressive lymphomas (19). In the last few years, the importance of MYC deregulation has become more apparent; it has been shown to be present in virtually all cases of BL $(12,20)$, and although present in a minority of DLBCL $(3-16 \%)(12,14)$, its presence in DLBCL is associated with poor response to treatment and a poor overall prognosis (21-23). This has made the detection of MYC translocation critical in the management of certain cases of DLBCL (24).

While Myc expression may be detected by IHC, MYC gene rearrangements are detected by other molecular techniques such as FISH. IHC is a routine method in most pathology laboratories; however, IHC analysis is based on a subjective interpretation of 


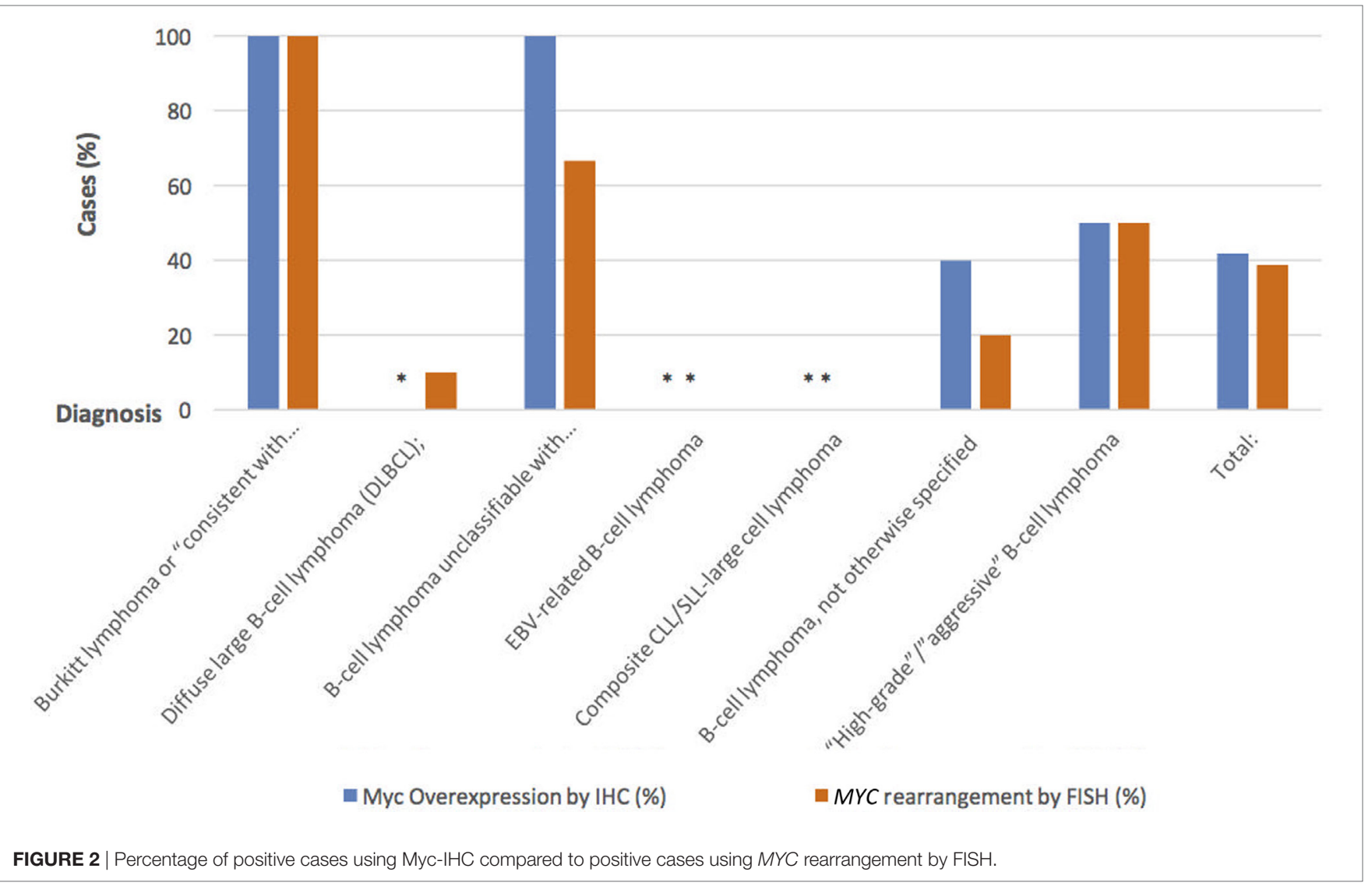

TABLE 2 | Sensitivity and specificity of Myc-IHC compared to MYC rearrangement by FISH.

\begin{tabular}{llcccc}
\hline & \multicolumn{3}{c}{$\begin{array}{c}\text { MYC rearrangement } \\
\text { by FISH }\end{array}$} & Total \\
\cline { 3 - 4 } & & Positive & Negative & \\
\hline \multirow{2}{*}{ Myc-IHC } & Positive & 11 & 2 & 13 & PPV $-84.6 \%$ \\
& Negative & 1 & 17 & 18 & NPV $-94.4 \%$ \\
& Total & $\mathbf{1 2}$ & $\mathbf{1 9}$ & $\mathbf{3 1}$ & \\
& & Sensitivity- & Specificity- & & \\
& $91.6 \%$ & $89.4 \%$ & & \\
& & &
\end{tabular}

staining intensity (25). IHC is also prone to poor tissue fixation, and there are some issues with reproducibility (26). Currently, FISH is the most sensitive and specific method for detection of oncogene amplification in human tissue samples and it is therefore seen as the gold standard method (26). The main advantages of FISH are its high sensitivity and specificity (16). Also, it is possible to analyze archival formalin-fixed tumor samples as DNA is less subject to effects of tissue fixation and processing than protein (26). In addition, internal controls can be included in each assay and results are quantitative (26). Nevertheless, the FISH method is laborious and demanding, which makes it time-consuming, highly trained personnel are required, and a fluorescence microscope is needed, which makes it a relatively expensive procedure. It is also difficult to study the detailed morphological features of a tumor as FISH signals fade over time (26).
Previous studies have demonstrated that Myc protein expression correlated with gene status in BL and DLBCL $(24,27,28)$. Tapia et al. also showed that overall, MYC translocated lymphomas had Myc nuclear positivity in $70 \%$ of neoplastic cells; in contrast to MYC non-translocated lymphomas that were positive in only $28 \%$ of the cells (27). This is consistent with the results of our study, which yielded a high sensitivity and specificity of Myc-IHC; 91.6 and $89.4 \%$, respectively. This is also in keeping with the studies of Lynnhtun et al. who demonstrated Myc-IHC sensitivity and specificity indices of 89 and $88 \%$ (at IHC positivity thresholds of $80 \%$ or more) (24). Kappa testing of our study showed the degree of agreement between both tests is 0.80 . This can be interpreted as a substantial agreement and satisfies the minimum inter rater agreement recommended by most authorities for laboratory tests (29).

Among our cases were two false positives (one case of B-cell lymphomas NOS and one case of B-cell lymphoma unclassifiable with features intermediate between DLBCL and $\mathrm{BL}$ ), which were also positive for polysomy of chromosome 8 . This could mean there is a dosage effect of the MYC gene as a reason for Myc overexpression as previously suggested by Gill et al. (30). However, this relationship is yet to be established in lymphomas.

We can, therefore, conclude that Myc-IHC predicts MYC rearrangements by FISH (the gold standard) with high sensitivity and specificity. We encountered no problems in the interpretation of $\mathrm{My}-\mathrm{IHC}$ in this cohort of cases. Despite our findings, it should be 
noted that our data were gotten from a small series. Additional studies on larger series could be appropriate to validate our findings. Nevertheless, we can postulate that Myc-IHC should be a potentially useful screening tool for identifying lymphomas that may harbor a MYC rearrangement as it is more widely available than FISH. It is also easier and quicker than FISH, thus offering potential cost and time savings. Furthermore, Myc-IHC may be of great usefulness in low resource centers that lack access to fluorescence microscopy.

\section{REFERENCES}

1. (US) NCfBI. The Reference Sequence (RefSeq) Project [Database Online]. Bethesda, MD: The NCBI Handbook (2016).

2. Duesberg PH, Bister K, Vogt PK. The RNA of avian acute leukemia virus MC29. Proc Natl Acad Sci U S A (1977) 74:4320-4. doi:10.1073/pnas.74.10.4320

3. Bister K, Jansen HW. Oncogenes in retroviruses and cells: biochemistry and molecular genetics. Adv Cancer Res (1986) 47:99-188. doi:10.1016/ S0065-230X(08)60199-2

4. Dalla-Favera R, Bregni M, Erikson J. Human c-myc onc gene is located on the region of chromosome 8 that is translocated in Burkitt lymphoma cells. Proc Natl Acad Sci U S A (1982) 79:7824-7. doi:10.1073/pnas.79.24.7824

5. Dang CV, Center for Cancer Research (National Cancer Institute (U.S.)). $M y c$, Metabolism, and Cancer. Bethesda, MD: NCI Center for Cancer Research Grand Rounds, National Institutes of Health (2015). 1 p. Online Resource [streaming video file (52 $\mathrm{min})$ ].

6. de Alboran IM, O'Hagan RC, Gartner F, Malynn B, Davidson L, Rickert R, et al. Analysis of C-MYC function in normal cells via conditional gene-targeted mutation. Immunity (2001) 14:45-55. doi:10.1016/ S1074-7613(01)00088-7

7. Habib T, Park H, Tsang M, de Alboran IM, Nicks A, Wilson L, et al. Myc stimulates B lymphocyte differentiation and amplifies calcium signaling. J Cell Biol (2007) 179:717-31. doi:10.1083/jcb.200704173

8. Ott G, Rosenwald A, Campo E. Understanding MYC-driven aggressive B-cell lymphomas: pathogenesis and classification. Blood (2013) 122:3884-91. doi:10.1182/blood-2013-05-498329

9. Morton LM, Wang SS, Devesa SS, Hartge P, Weisenburger DD, Linet MS. Lymphoma incidence patterns by WHO subtype in the United States, 1992-2001. Blood (2006) 107:265-76. doi:10.1182/blood-2005-06-2508

10. Oschlies I, Klapper W, Zimmermann M, Krams M, Wacker HH, Burkhardt $\mathrm{B}$, et al. Diffuse large B-cell lymphoma in pediatric patients belongs predominantly to the germinal-center type B-cell lymphomas: a clinicopathologic analysis of cases included in the German BFM (Berlin-Frankfurt-Munster) Multicenter Trial. Blood (2006) 107:4047-52. doi:10.1182/blood-2005$10-4213$

11. Nesbit CE, Tersak JM, Prochownik EV. MYC oncogenes and human neoplastic disease. Oncogene (1999) 18:3004-16. doi:10.1038/sj.onc.1202746

12. Zhao XF, Hassan A, Perry A, Ning Y, Stass SA, Dehner LP. C-MYC rearrangements are frequent in aggressive mature B-Cell lymphoma with atypical morphology. Int J Clin Exp Pathol (2008) 1:65-74.

13. Hoffman R. Hematology: Basic Principles and Practice. 5th ed. Philadelphia, PA: Churchill Livingstone/Elsevier (2009).

14. Slack GW, Gascoyne RD. MYC and aggressive B-cell lymphomas. Adv Anat Pathol (2011) 18:219-28. doi:10.1097/PAP.0b013e3182169948

15. Gocke CD. c-Myc immunohistochemistry in diffuse large B cell lymphoma [review]. Pathol Case Rev (2014) 19(5):234-8. doi:10.1097/ PCR.0000000000000058

16. Rummukainen JK, Salminen T, Lundin J, Joensuu H, Isola JJ. Amplification of c-myc oncogene by chromogenic and fluorescence in situ hybridization in archival breast cancer tissue array samples. Lab Invest (2001) 81:1545-51. doi:10.1038/labinvest. 3780368

17. Tzankov A, Xu-Monette ZY, Gerhard M, Visco C, Dirnhofer S, Gisin N, et al. Rearrangements of MYC gene facilitate risk stratification in diffuse large B-cell lymphoma patients treated with rituximab-CHOP. Mod Pathol (2014) 27:958-71. doi:10.1038/modpathol.2013.214

18. Anti-c-Myc [Y69] Antibody (ab32072). (2014)

\section{AUTHOR CONTRIBUTIONS}

JN participated in the research and also helped with the statistical analysis done. He was the principal author of the manuscript. MS helped plan and participated in the research and contributed to the review of the manuscript. KS helped plan and participated in the research. DS helped plan and carry out the research. CC helped plan the experiment and also contributed to the review of the manuscript.

19. Adams JM, Harris AW, Pinkert CA, Corcoran LM, Alexander WS, Cory S, et al. The c-myc oncogene driven by immunoglobulin enhancers induces lymphoid malignancy in transgenic mice. Nature (1985) 318:533-8. doi:10.1038/318533a0

20. Boxer LM, Dang CV. Translocations involving c-myc and c-myc function. Oncogene (2001) 20:5595-610. doi:10.1038/sj.onc.1204595

21. Klapper W, Stoecklein H, Zeynalova S, Ott G, Kosari F, Rosenwald A, et al. German high-grade non-Hodgkin's lymphoma study G: structural aberrations affecting the MYC locus indicate a poor prognosis independent of clinical risk factors in diffuse large B-cell lymphomas treated within randomized trials of the German High-Grade Non-Hodgkin's Lymphoma Study Group (DSHNHL). Leukemia (2008) 22:2226-9. doi:10.1038/leu.2008.230

22. Yoon SO, Jeon YK, Paik JH, Kim WY, Kim YA, Kim JE, et al. MYC translocation and an increased copy number predict poor prognosis in adult diffuse large B-cell lymphoma (DLBCL), especially in germinal centre-like B cell (GCB) type. Histopathology (2008) 53:205-17. doi:10.1111/j.1365-2559.2008.03076.x

23. Barrans S, Crouch S, Smith A, Turner K, Owen R, Patmore R, et al Rearrangement of MYC is associated with poor prognosis in patients with diffuse large B-cell lymphoma treated in the era of rituximab. J Clin Oncol (2010) 28:3360-5. doi:10.1200/JCO.2009.26.3947

24. Lynnhtun K, Renthawa J, Varikatt W. Detection of MYC rearrangement in high grade B cell lymphomas: correlation of MYC immunohistochemistry and FISH analysis. Pathology (2014) 46:211-5. doi:10.1097/PAT.0000000000000076

25. Wolff AC, Hammond ME, Hicks DG, Dowsett M, McShane LM, Allison KH, et al. Recommendations for human epidermal growth factor receptor 2 testing in breast cancer: American Society of Clinical Oncology/College of American Pathologists clinical practice guideline update. J Clin Oncol (2013) 31:3997-4013. doi:10.1200/JCO.2013.50.9984

26. Tabarestani S, Ghaderian SM, Rezvani H. Detection of gene amplification by multiplex ligation-dependent probe amplification in comparison with in situ hybridization and immunohistochemistry. Asian Pac J Cancer Prev (2015) 16:7997-8002. doi:10.7314/APJCP.2015.16.17.7997

27. Tapia G, Lopez R, Munoz-Marmol AM, Mate JL, Sanz C, Marginet R, et al. Immunohistochemical detection of MYC protein correlates with MYC gene status in aggressive B cell lymphomas. Histopathology (2011) 59:672-8. doi:10.1111/j.1365-2559.2011.03978.x

28. Green TM, Nielsen O, de Stricker K, Xu-Monette ZY, Young KH, Moller MB. High levels of nuclear MYC protein predict the presence of MYC rearrangement in diffuse large B-cell lymphoma. Am J Surg Pathol (2012) 36:612-9. doi:10.1097/PAS.0b013e318244e2ba

29. McHugh ML. Interrater reliability: the kappa statistic. Biochem Med (Zagreb) (2012) 22:276-82. doi:10.11613/BM.2012.031

30. Gill KZ, Iwamoto F, Allen A, Hoehn D, Murty VV, Alobeid B, et al. MYC protein expression in primary diffuse large B-cell lymphoma of the central nervous system. PLoS One (2014) 9:e114398. doi:10.1371/journal.pone.0114398

Conflict of Interest Statement: The authors declare that the research was conducted in the absence of any commercial or financial relationships that could be construed as a potential conflict of interest.

Copyright $\odot 2017$ Nwanze, Siddiqui, Stevens, Saxe and Cohen. This is an open-access article distributed under the terms of the Creative Commons Attribution License (CC BY). The use, distribution or reproduction in other forums is permitted, provided the original author(s) or licensor are credited and that the original publication in this journal is cited, in accordance with accepted academic practice. No use, distribution or reproduction is permitted which does not comply with these terms. 